Research Paper

\title{
The inhibition of indoleamine 2, 3-dioxygenase 1 by connexin 43
}

\author{
Han-Chen Lin', Chih-Jen Yang2, Yu-Diao Kuan ${ }^{3}$, Wei-Kuang Wang 4, Wen-Wei Chang 5,6, Che-Hsin Lee \\ $3,7 \bowtie$ \\ 1. Department of Anatomy, School of Medicine, College of Medicine, Kaohsiung Medical University, Kaohsiung, Taiwan; \\ 2. Department of Internal Medicine, College of Medicine, Kaohsiung Medical University, Kaohsiung, Taiwan; \\ 3. Department of Biological Sciences, National Sun Yat-sen University, Kaohsiung 804, Taiwan; \\ 4. Department of Environmental Engineering and Science, Feng Chia University, Taichung 404, Taiwan; \\ 5. Department of Biomedical Sciences, College of Medical Science and Technology, Chung Shan Medical University, Taichung, Taiwan \\ 6. Department of Medical Research, Chung Shan Medical University Hospital, Taichung, Taiwan \\ 7. Department of Medical Research, China Medical University Hospital, China Medical University, Taichung 404, Taiwan
}

$\square$ Corresponding author: Dr. Che-Hsin Lee, Department of Biological Sciences, National Sun Yat-sen University, Kaohsiung, Taiwan, 70 Lienhai Rd. Kaohsiung 80424, Taiwan. E-mail: chlee@mail.nsysu.edu.tw

(c) Ivyspring International Publisher. This is an open access article distributed under the terms of the Creative Commons Attribution (CC BY-NC) license (https://creativecommons.org/licenses/by-nc/4.0/). See http://ivyspring.com/terms for full terms and conditions.

Received: 2017.04.19; Accepted: 2017.08.21; Published: 2017.09.19

\begin{abstract}
Upregulation of connexin $43(\mathrm{Cx} 43)$ showed potential in enhancing immune surveillance that was suppressed in the tumor microenvironment. The expression of indoleamine 2, 3-dioxygenase (IDO) is one of the crucial factors contributing to tumor immune tolerance by depletion of tryptophan and IDO-mediated tryptophan metabolites. Here, we aim to investigate the role of Cx43 in IDO production in murine tumor by using Cx43 inducers. Resveratrol (trans-3, 5, 4 '-trihydroxystilbene) is a natural plant-derived polyphenol possessing positive effect against cancer. Salmonella enterica serovar choleraesuis (S.C.) was proved to target and inhibit tumor growth. Both of them regulated $\mathrm{C} \times 43$ expression in tumor cells and led to either chemosensitizing or immune-activating. In this study, the correlation between $\mathrm{Cx} 43$ and IDO were determined by the treatment of resveratrol and S.C. Our data showed an increase in Cx43 while IDO protein and IDO-mediated inhibited effects on $\mathrm{T}$ cell decreased after tumor cells are given with resveratrol and S.C. treatments. All of which could be inhibited once the expression of $\mathrm{C} \times 43$ was blocked. $\mathrm{C} \times 43$ involved in IDO regulation might be useful in developing IDO-targeted cancer immune therapy.
\end{abstract}

Key words: connexin 43, indoleamine 2, 3-dioxygenase 1, resveratrol, Salmonella

\section{Introduction}

The impaired ability of antigen presentation of cancer cells can be restored by enhancement of gap-junction-forming molecule, connexin 43 (Cx43) [1, 2]. Consisting two connexons and each composed of six connexins, gap junction is responsible for cell-cell molecule transferring and homeostasis maintenance [3]. Cx43, one of the wildly-studied connexin isoform, is considered to have correlation with immunity, disease formation and progression $[4,5]$. The lack of Cx43 induced by hypoxia renders melanoma more resistant to natural kill cell mediated lysis whereas its accumulation can restore the phenomenon by the formation of immune synapse and also involves inactivation of $\mathrm{T}$ cells [6-8]. Indoleamine 2, 3-dioxygenase 1 (IDO) involves in one mechanism by which tumor cells avoid immune surveillance. As an enzyme initiating first and rate-limiting step of the tryptophan metabolic pathway, IDO mediates depletion of tryptophan and accumulation of tryptophan catabolites, thus leading to effector $\mathrm{T}$ cell apoptosis and activation of regulatory $\mathrm{T}$ cells (Treg) [9]. The inhibition of IDO production is able to activate host immunity [10, 11]. The combination of chemotherapy drugs and the IDO inhibitor were evaluated the beneficial effect in ongoing clinical studies, indicating IDO might be promising in 
developing cancer immunotherapeutic treatment [12, 13].

In this study, we investigated the signaling pathway responsible for this process after two immune-activating agent, resveratrol and Salmonella enterica serovar choleraesuis (S. Choleraesuis, S.C.). Resveratrol (trans-3, 5, 4 '-trihydroxystilbene) is a phytoalexin found in several plant species in response to environmental stress [14]. It was exerted in cancer prevention and inhibition contributes to antioxidant and anti-proliferative properties [14-16]. Moreover, several researches showed the beneficial effects of resveratrol on inhibition of cancer by inactivating tumor-induced tolerance and modulation of cytokine production [17-20].

On the other hand, bacteria were observed by a sarcoma surgeon to inhibit tumor growth in the 19th century [21]. As a facultative anaerobe with motility, Salmonella is more preferentially reaching, accumulating and proliferating in the tumor region than other strains or drugs [22-23]. Salmonella could inhibit the immune tolerance of tumor and activate the host immunity [7, 24, 25]. Herein, the treatment of S.C. or resveratrol in melanoma cells were demonstrated the ability of reducing IDO production through upregulating Cx43.

\section{Materials and Methods}

\section{Bacteria, reagents and cell line}

Vaccine strain Salmonella enterica serovar choleraesuis (S. Choleraesuis; S.C.) (ATCC 15480) was obtained from Bioresources Collection and Research Center (Hsinchu, Taiwan). Bacteria were maintained in L.B. plate and propagate in L.B. broth for using. Resveratrol (0-6 $\mu \mathrm{g} / \mathrm{ml}$.), and DMSO were purchased from Sigma Aldrich (Sigma Aldrich, St. Louis, MO, USA). Murine B16F10 cells were maintained in culture dish with Dulbecco's Modified Eagle Medium (DMEM) containing 1\% Penicillin-Streptomycin (100 units/mL penicillin and $100 \mu \mathrm{g} / \mathrm{mL}$ streptomycin), $2 \mathrm{mM}$ glutamine and $10 \%$ heat-inactivated fetal bovine serum. Jurkat cell line (human T lymphocyte; (ATCC TIB-152 $\left.{ }^{\mathrm{TM}}\right)$ ) was a kind gift from Professor Wen-Wei Chang (Chung Shan Medical University) and maintained in HyClone RPMI 1640 medium containing $10 \%$ FBS. All cells were passaged every two to three days and incubated at $37^{\circ} \mathrm{C}, 5 \% \mathrm{CO} 2$.

\section{Knockdown of Cx43}

The specific shRNA of Cx43 plasmids were purchased from Santa Cruz Biotechnology (sc-35091-SH, Santa Cruz Bio-technology, Santa Cruz, CA, USA). B16F10 were transfected with Cx43 shRNA plasmids $(5 \mu \mathrm{g})$ by lipofectamine 2000 (Thermo
Scientific, Rockford, IL. USA) in Opti-MEM I reduced serum media (Thermo Scientific). Medium would be replaced with 10\% DMEM after $16 \mathrm{~h}$. The siRNA oligos of Cx43 designed to knockdown gene expression and the target sequences were listed below: Cx43 siRNA73 CCTGCTGATCCAGTGGTACATCTAT and Cx43 siRNA94 GCGTGAAGGGAAGAAGCGATCCTTA. Lipofectamine RNAiMax reagent (Invitrogen, Carlsbad, CA, USA) was used for siRNA transfection following the manufacturer's protocol.

\section{Analysis of Cx43 transcriptional activity}

Cells grown in 24-well plates were cotransfected with luciferase reporter plasmids driven by $\mathrm{Cx} 43$ promoters $(0.66 \mu \mathrm{g})$ and pTCYLacZ (0.34 $\mu \mathrm{g})$, a $\beta$-galactosidase $(\beta$-gal) expression plasmid driven by the $\beta$-actin promoter, by lipofectamine 2000 (Invitrogen). At $6 \mathrm{~h}$ post-transfection, cells were treated with resveratrol or S.C. and cell lysates were harvested at different concentrations. The cell lysates were assessed for their luciferase activities determined by a dual-light luciferase and $\beta$-gal reporter gene assay system (Promega, Madison, WI, USA) using a luminometer (Minilumate LB9506, Bad Wildbad). Relative luciferase activity was measured as luciferase activity divided by $\beta$-gal activity to normalize transfection efficiency per microgram protein. The protein content in each sample was determined by the BCA protein assay (Pierce).

\section{Western blot analysis}

The protein content in each sample was determined by bicinchoninic acid (BCA) protein assay (Pierce Biotechnology, Rockford, IL, USA). Quantified each sample concentration to 60-80 $\mu \mathrm{g}$ and add $4 \times$ SDS sample dye and then sample were denatured for $10 \mathrm{~min}$ at $95^{\circ} \mathrm{C}$. Proteins were fractionated on SDS-PAGE, transferred onto Hybond enhanced chemiluminescence nitrocellulose membranes (Amersham, Little Chalfont, UK) and detected with antibodies against IDO (Thermo Scientific), Cx43 (Sigma-Aldrich) and $\beta$-actin (Sigma-Aldrich). Rabbit anti-mouse IgG-peroxidase antibody (Sigma-Aldrich) and goat anti-rabbit IgG-peroxidase antibody (Sigma-Aldrich) were used as the secondary antibody and protein-antibody complexes were visualized by enhanced chemiluminescence system (Amersham). The signals were quantified with ImageJ software (rsbweb.nih.gov/ij).

\section{IDO functional assay}

All cells incubations were at $37^{\circ} \mathrm{C}, 5 \% \mathrm{CO}_{2}$. B16F10 cells were plated in 12 well waited for attachment, and incubated with either different the multiplicity of infection (MOI) of Salmonella for $1.5 \mathrm{~h}$ 
or various concentrations of resveratrol for $24 \mathrm{~h}$. The medium of cells treated with Salmonella would be replaced with gentamicin-contained medium after bacteria incubation for $24 \mathrm{~h}$. $160 \mu \mathrm{l}$ of supernatants were harvested with $10 \mu \mathrm{l} 30 \%$ TCA (Sigma-Aldrich) at $50^{\circ} \mathrm{C}, 30 \mathrm{~min}$ and then centrifuged mixture at 3000 $\mathrm{rpm}$ for $20 \mathrm{~min}$ at RT. The $125 \mu \mathrm{l}$ mixture were mixed in an equal amount of $125 \mu \mathrm{l}$ Erchlich' s reagent (Sigma-Aldrich) in acetic acid in 96-well plates for 10 min. The absorbances of kynurenine were detected by spectrophotometer at a wavelength of A490. The data were performed as percentage of control. All of the IDO functional assays were done in quadruplicate.

\section{Cell viability assay}

Tumor cells were plated in 6 well culture plates and treated with various MOI of Salmonella for $1.5 \mathrm{~h}$ or various concentrations of resveratrol for $24 \mathrm{~h}$ after cells had been attached. The supernatants of Salmonella-treated B16F10 or 4T1 were added to Jurkat cells mixed with equal amount of RPMI medium. After 3 days, cell survival was assessed using the trypan blue exclusion assay. All of the viability assays were done in quadruplicate or sextuplicate.

\section{Statistical analysis}

All data were expressed as mean \pm standard deviation (SD). The unpaired, two-tailed Student's $t$ test was used to determine differences between groups. Any $P$ value less than 0.05 is regarded statistically significant.

\section{Results}

\section{The correlation between Cx43 and IDO}

Cx43 has been demonstrated as a tumor suppressor, and interact with various molecules [26]. This study aims to identify the relationship between Cx43 and IDO in tumor cells. First, we used Western blotting to measure the expression of Cx43 and IDO in a variety of murine tumor cells (Fig 1A). The expression of Cx43 in CT26 (murine colon cancer) and 4T1 (murine breast cancer) cells was higher than that in B16F10 (murine melanoma) cells, but the expression of IDO in CT26 and 4T1 cells was not significantly different between that in B16F10 cells. The expression of Cx43 in B16F10 cells was lower than that in K1735 (murine melanoma) cells. The K1735 cell with higher Cx43 expressed lower IDO relatively. The B16F10 cells with the lowest $\mathrm{C} \times 43$ and higher IDO expression was chosen in further experiments. The correlation between $\mathrm{Cx} 43$ and IDO were identified in Cx43-knockdown B16F10 cell lines. Both Cx43 knockdown B16F10 cell lines \#2 and \#3 showed higher IDO expression (Fig 1B). To confirm the results,
IDO-mediated tryptophan metabolites, kynurenine was evaluated. The accumulation of kynurenine and starvation of tryptophan lead to $\mathrm{T}$ cell apoptosis, causing immune suppression within the tumor microenvironment [27]. A higher production of kynurenine in Cx43 knockdown B16F10 cell lines \#2 and \#3 was observed in Fig 1C. These results suggested Cx43 might be related to IDO and IDO-mediated activity.

\section{Resveratrol and Salmonella upregulated Cx43 and inhibited IDO expression in melanoma cells}

Previously, other and our studies found that Salmonella (Salmonella enterica serovar choleraesuis ( $S$. Choleraesuis; S.C.) (ATCC 15480)) and resveratrol could enhance the expression of $\mathrm{C} 43[2,27]$. Hererin, the resveratrol and Salmonella as Cx43 activators were used to further evaluate the correlation between Cx43 and IDO. The results performed the upregulation of Cx43 by resveratrol (Fig. 2) and Salmonella (Fig. 3) accompanying the reduction in IDO and kynurenine production. Both of them possessed the ability of increasing Cx43 expression (Fig. 2A and Fig. 3A). Meanwhile, we examined the effect of resveratrol or S.C. on the Cx43 transcriptional activity by the luciferase reporter assay (Fig. 2B and Fig. 3B). The extent of Cx43 transcriptional activity of resveratrol or S.C. treatment in melanoma cells varied, ranging from 1.2 to 2.4 folds. A dose-dependently increase in Cx43 expression was regulated by resveratrol or Salmonella. On the contrary, IDO was downregulated both by resveratrol and Salmonella in dose-dependent manner. A low level of kynurenine production in resveratrol or Salmonella-treated groups (Fig. 2C and Fig. 3C). Next, the effect of kynurenine on $\mathrm{T}$ cell viability was performed in Fig. 2D and Fig. 3D. The conditioned medium from tumor cells treated with resveratrol or Salmonella increased the proliferation of $\mathrm{T}$ cell compared with control group (Fig. 2D and Fig. 3D). The results demonstrated that $\mathrm{C} \times 43$ activators reduced the expression and function of IDO in tumor cells.

\section{Inhibited IDO expression by upregulation of Cx43}

To confirm the role of $\mathrm{C} \times 43$ in regulation of IDO, Cx43 RNA interference (RNAi) were transfected to B16F10 to block Cx43 expression prior to the treatment of resveratrol or Salmonella. Since the Cx43 expression reach the highest level in $4 \mu \mathrm{g} / \mathrm{ml}$ of resveratrol and $100 \mathrm{MOI}$ of Salmonella, the next experiments were all followed by the two concentrations. Cells transfected with Cx43 RNAi \#73 showed better ability in reduction Cx43 expression whereas Cx43 RNAi \#94 had less affect. After administrated with resveratrol (4 
$\mu \mathrm{g} / \mathrm{ml})$ or Salmonella $(\mathrm{MOI}=100)$ with lower expression of Cx43 showed little change of IDO while IDO in control groups was still inhibited after the administration (Fig. 4A and 5A), and either was the production of kynurenine in RNAi transfected-groups (Fig. 4C and 5B). The Cx43 RNAi did not influence the promoter activity (Fig. 4B). The blockade of Cx43 also prevented $\mathrm{T}$ cell proliferation being restored by resveratrol and Salmonella treatment (Fig. 4D and 5C). These data proved that $\mathrm{C} \times 43$ might be crucial in resveratrol and Salmonella-controlling IDO and tryptophan metabolites production.
A

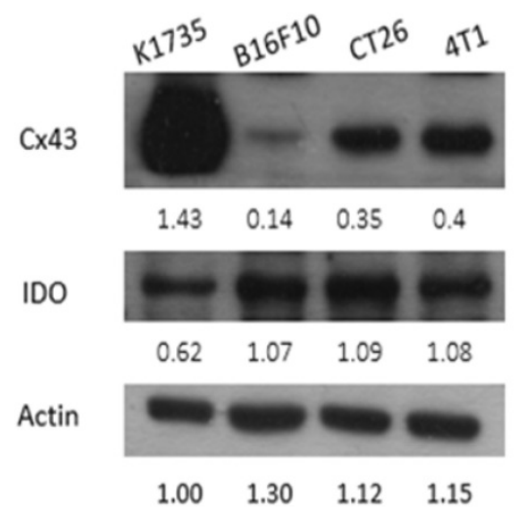

B

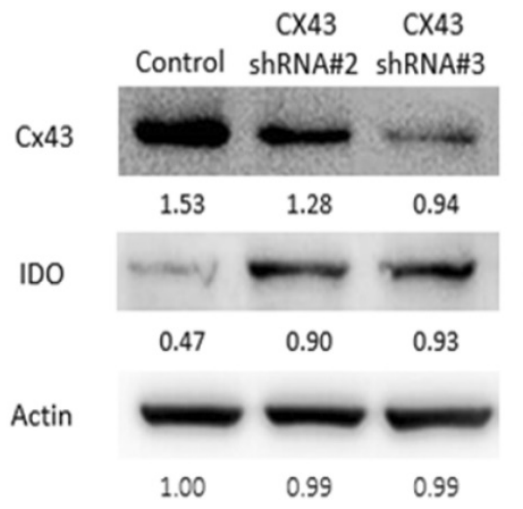

C

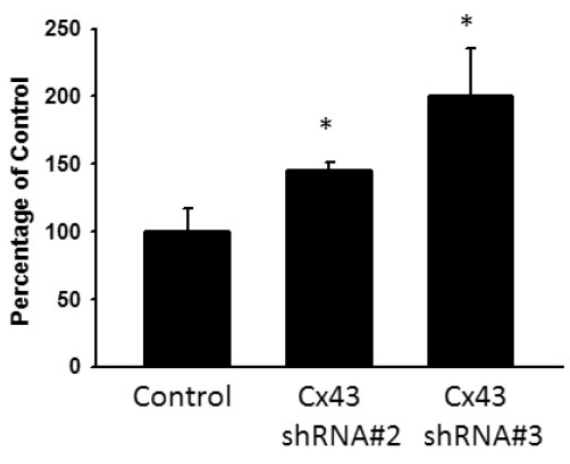

Figure 1. Cx43, IDO and kynurenine expression varies in different cancer cell lines. (A) The IDO and Cx43 protein level of different cancer cell lines, K1735, B16F10, CT26 and 4T1 were determined by Western blotting. (B) The IDO and Cx43 protein levels in Cx43-knockdown B16F10 cell lines were determined (C) The kynurenine production in Cx43-knockdown B16F10 cell lines were measured by kynurenine assay. $(\mathrm{n}=3$, data are mean \pm SD. $* P<0.05$, $* * P<0.01$, $* * * P<0.001)$.
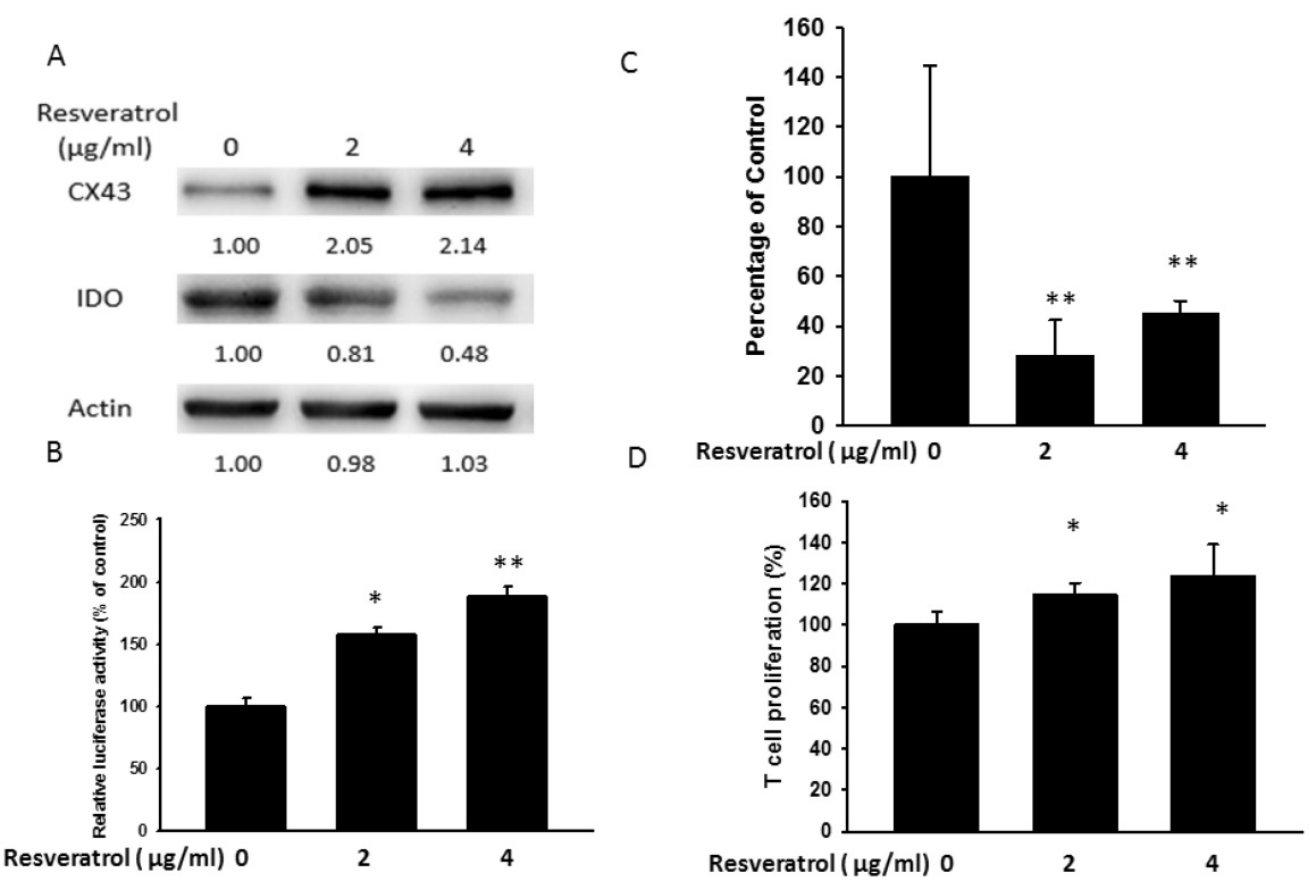

Figure 2. Resveratrol inhibited IDO expression dose dependently. B16F10 cells (106) were treated with different concentrations of resveratrol $(0-4 \mathrm{\mu g} / \mathrm{ml})$ for $24 \mathrm{~h}$. (A) The IDO and Cx43 protein levels of resveratrol were determined by Western blotting. (B) B16F10 cells transfected with luciferase gene under the control of Cx43 promoter were treated with resveratrol $(0-4 \mu \mathrm{g} / \mathrm{ml})$ for $24 \mathrm{~h}$. The transcriptional activity of Cx43 was determined by the luciferase reporter assay and is expressed as the fold of the relative luciferase activity relative to that in the control tumor cells. (C) The kynurenine production were measured by kynurenine assay. (D) Supernatants were collected after $24 \mathrm{~h}$ resveratrol incubation, and harvested Jurkat cells with equal amount of RPMI. 3 days later, Jurkat cells were stained with trypan blue to measure proliferation rate. $(n=4$, data are mean \pm SD. $* P<0.05$, $* * P<0.01)$. 
A

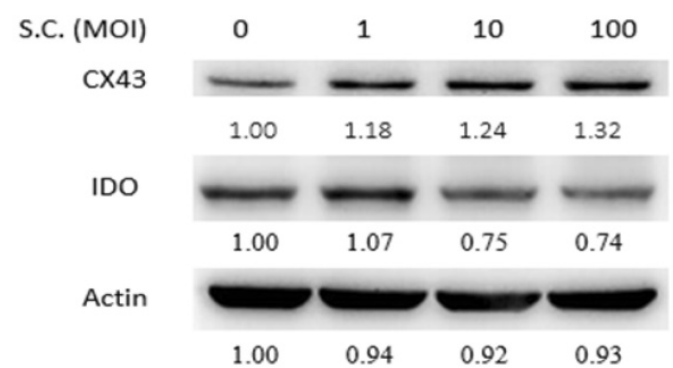

B

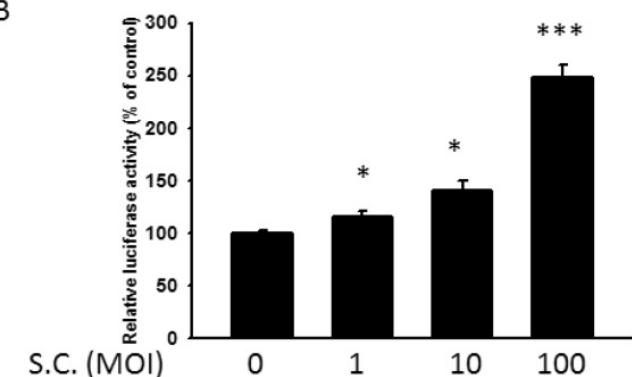

C

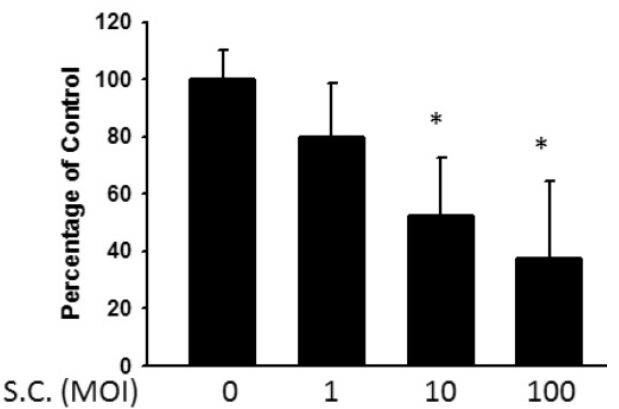

D

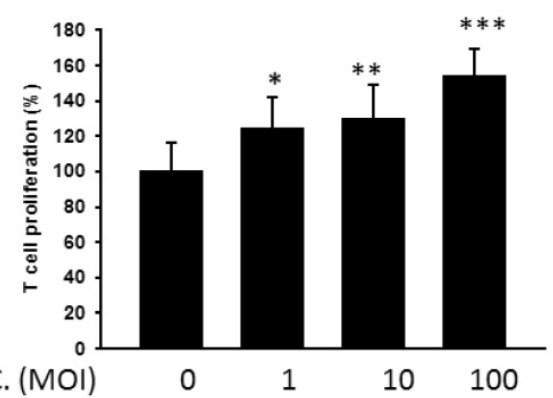

Figure 3. Salmonella (S.C.) inhibited IDO expression. B16F10 cells were treated with various MOI of S.C. (0-100) for $1.5 \mathrm{~h}$ and replaced medium with gentimicin-containing medium to kill bacteria. (A) The protein levels of IDO and Cx43 after resveratrol treatment were determined by Western blotting. (B) B16F10 cells transfected with luciferase gene under the control of $\mathrm{Cx} 43$ promoter were treated with S.C. $(\mathrm{MOI}=0-100)$ for $24 \mathrm{~h}$. The transcriptional activity of $\mathrm{Cx} 43$ was determined by the luciferase reporter assay and is expressed as the fold of the relative luciferase activity relative to that in the control tumor cells. (C) The kynurenine production were measured by kynurenine assay. (D) Supernatants were collected after $24 \mathrm{~h}$ resveratrol incubation, and harvested Jurkat cells with equal amount of RPMI. 3 days later, Jurkat cells were stained with trypan blue to measure proliferation rate. $(\mathrm{n}=4$, data are mean $\pm \mathrm{SD}$. $* P<0.05, * * P<0.01, * * * P<0.001)$.
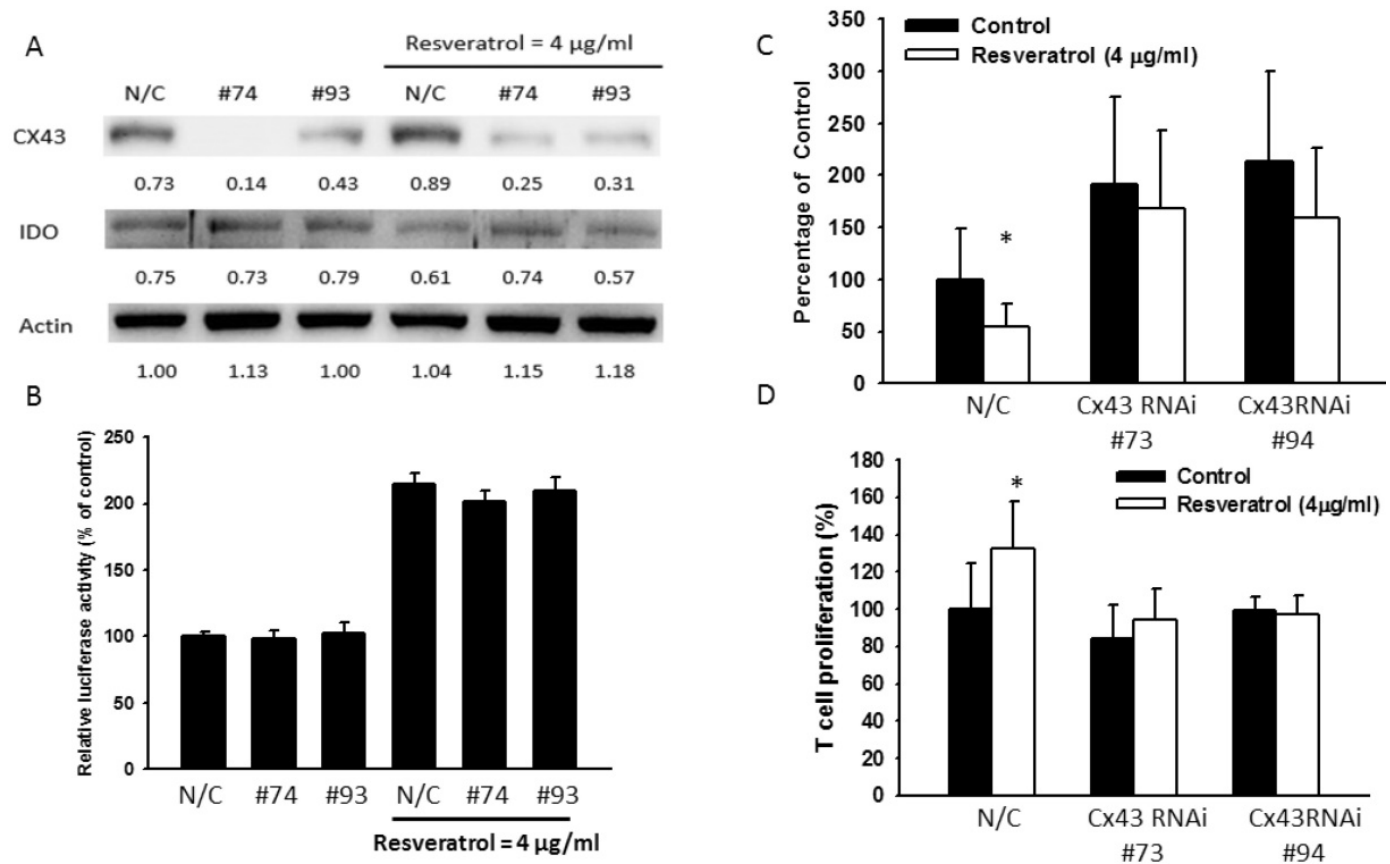

Figure 4. Resveratrol inhibited IDO expression through upregulating Cx43. B16F10 cells were transfected with Cx43 RNAi. Medium were replaced with $10 \%$ FBS contained DMEM. Transfected cells were treated with $4 \mu \mathrm{g} / \mathrm{ml}$ resveratrol for $24 \mathrm{~h}$. (A) The IDO and Cx43 protein level of resveratrol were determined by Western blotting. (B) B16F10 or Cx43 knockdown cells transfected with luciferase gene under the control of Cx43 promoter were treated with resveratrol (4 $\mu \mathrm{g} / \mathrm{ml})$ for 24 $\mathrm{h}$. The transcriptional activity of $\mathrm{C} \times 43$ was determined by the luciferase reporter assay and is expressed as the fold of the relative luciferase activity relative to that in the control tumor cells. (D) The kynurenine production were measured by kynurenine assay. (C) Supernatants were collected after $24 \mathrm{~h}$ resveratrol incubation, and harvested Jurkat cells with equal amount of RPMI. 3 days later, Jurkat cells were stained with trypan blue to measure proliferation rate. $(n=6$, data are mean \pm SD. $* P<0.05)$. 

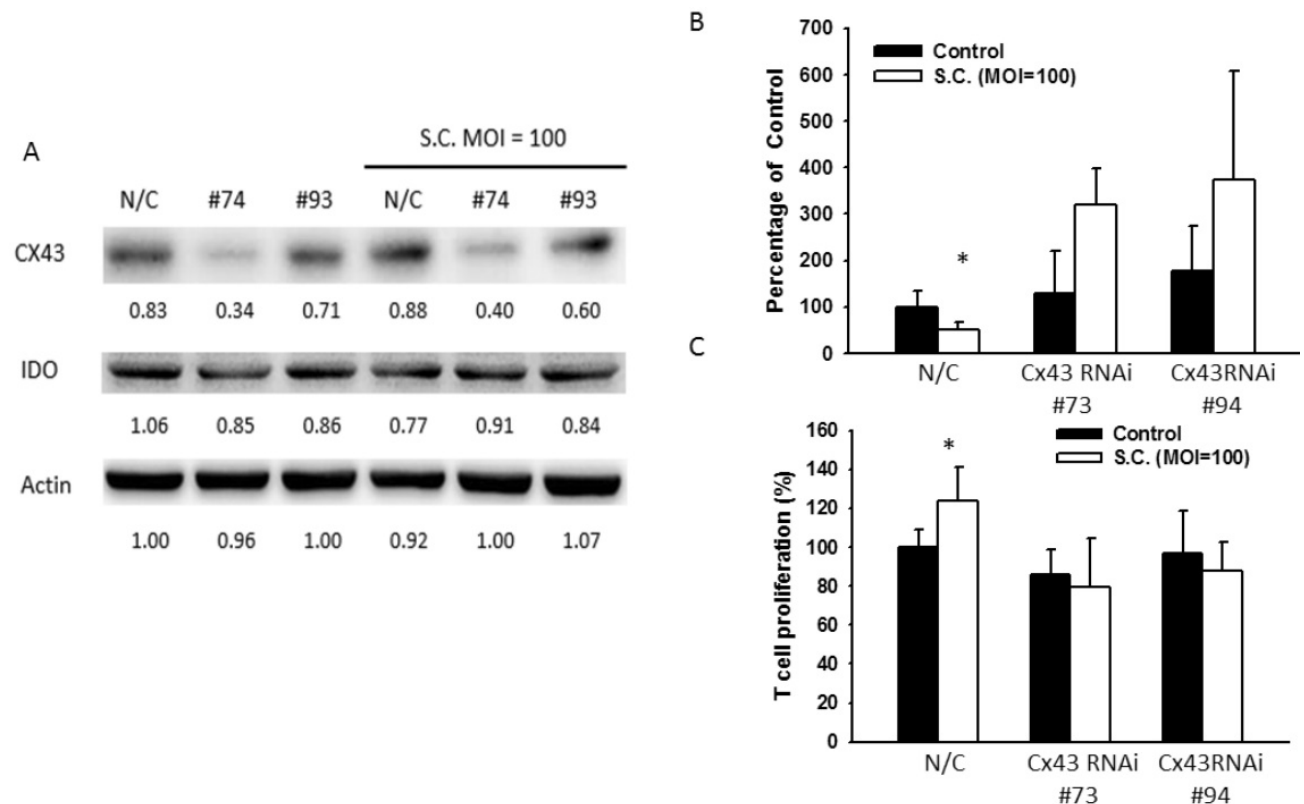

Figure 5. Salmonella (S.C.) inhibited IDO expression through upregulating Cx43. B16F10 cells were transfected with Cx43 RNAi. Medium were replaced with $10 \%$ FBS contained DMEM. Transfected cells were treated with Salmonella (MOI=100). (a) The IDO and Cx43 protein level were determined by Western blotting after Salmonella treatment. (B) The kynurenine production were measured by kynurenine assay. (C) Supernatants were collected after $24 \mathrm{~h}$ resveratrol incubation, and harvested Jurkat cells with equal amount of RPMI. 3 days later, Jurkat cells were stained with trypan blue to measure proliferation rate. ( $n=6$, data are mean \pm SD. $* P<0.05)$.

\section{Discussion}

In this study, we investigated the molecular mechanism that Cx43 involves in IDO regulation. The expression of $\mathrm{C} \times 43$ varies in different cancer cell lines and cells with lower Cx43 exhibited a higher IDO level, indicating Cx43 might correlate with IDO expression. Then, resveratrol and Salmonella which have been reported to upregulate $\mathrm{C} \times 43$ were exerted to evaluate the Cx43-IDO signaling pathway. The administration of resveratrol and Salmonella in B16F10 increased $\mathrm{Cx} 43$ expression with reduced protein level of IDO and kynurenine content significantly. Furthermore, knockdown of Cx43 inhibited the resveratrol and Salmonella-mediated IDO reduction, indicating $\mathrm{C} \times 43$ might be crucial in regulation of tumor-releasing IDO. Moreover, the treatment of well-known IDO inducer, interferon- $\gamma$ (IFN- $\gamma)$ [28], was not used in our experiment because IDO and Cx43 protein expressed the same pattern after IFN- $\gamma$ treatment, indicating $\mathrm{Cx} 43$ might not be the main regulator in IFN- $\gamma$-induced IDO expression (data not shown). In spite of the success in vivo experiment, the utilization of resveratrol and Salmonella in clinical studies still encountered several problems. Rapid metabolism made resveratrol hard to maintain therapeutic effect in blood level [29]. Administration of resveratrol did not achieve the expected results on established cancer and safety concerns were observed in multiple myeloma patients with kidney problems [30, 31]. Gene modified strain Salmonella, VNP20009, showed low colonization in phase I melanoma clinical trial [32]. The unexpected outcome might contribute to lack of lipid A and impaired ability of producing purine which was known to be expressed poorly in melanoma $[33,34]$. The alternation of biosynthesis based on safety concerns made gene-modified strain applied to limited cancer type. Hence, current researches focused on supportive role of Salmonella or resveratrol in chemoresistance, anti-angiogenesis and immune modulation etc. rather than their direct toxicity to tumor cells [24, 26, 35-38]. Here, we identified the potential of resveratrol and Salmonella that regulating $\mathrm{C} \times 43$ and IDO. Ino and colleagues demonstrated the high expression of IDO in endometrial cancer clinical surgical specimen has correlation with disease progression and poor prognosis [39]. Being sensitive to tryptophan, T cells sense IDO-mediated tryptophan depletion by uncharged tRNAs and trigger kinase general control non-depressible 2 (GCN2) resulting in cell cycle arrest and CD8+ T cells anergy [40]. The binding of tryptophan metabolites and aryl hydrocarbon receptor (AHR) involves in the differentiation of naïve helper T cells (Th) to Treg phenotype. Moreover, IDO serves as a signaling protein triggered by transforming growth factor- $\beta$ (TGF- $\beta$ ) is responsible for maintain long-term tolerance [41]. 1-methyl-tryptophan (1-MT) is now a widely studied tryptophan analog with higher affinity to IDO thus abrogating the IDO-mediated immune tolerance. One of 1-MT isoform, 1-methyl-D-tryptophan was 
conducted in several ongoing clinical trials [5]. However, one still cast doubts on IDO-inhibited ability of 1-MT since an upregulation of IDO was seen in 1-MT-treated cancer cells [42]. The other IDO selective inhibitor, Epacadostat, also possesses higher affinity to IDO than tryptophan without affecting other IDO-related enzyme, was also exerted in several ongoing clinical trial accompanied with other chemotherapeutic drugs, while the correlation between results and biomarkers still being evaluating [43]. Cx43 used to be classified as tumor suppressor gene, however, new evidence indicated the role of Cx43 in tumor progression depends on cancer stage [44]. Evidence showed that Cx43 and Cx43-mediated gap junction is important in forming immune synapse and activating $\mathrm{T}$ cells by regulating $\mathrm{Ca} 2+$ signals. The data also performed $\mathrm{C} \times 43$ and $\mathrm{C} \times 43$-mediated gap junction involved in the regulation of IFN- $\gamma$ since the inhibition of which abrogated secretion of IFN- $\gamma$ in T cells [6]. The upregulation of $\mathrm{C} \times 43$ and its mediated functional gap junction in tumor cells facilitated antigen transferring between immune cells and tumor cells, thus contributing to antitumor response [1, 2]. The other studies also pointed out that the silencing Cx43 suppressed synovial fibroblast-releasing pro-inflammatory cytokines such as IFN- $\gamma$, tumor necrosis factor- $\alpha$ (TNF- $\alpha$ ) which should have been stimulated by lipopolysaccharides [5]. These findings inferred the importance of $\mathrm{Cx} 43$ in regulating immunity. In this article, our results identified the underlying molecular mechanism that $\mathrm{C} \times 43$ controlled IDO and IDO-mediated metabolites. Our findings might raise further investigation of Cx43-related tumor immune tolerance and highlight the potential of $\mathrm{C} \times 43$ and IDO in developing anticancer treatment.

\section{Abbreviations}

IDO: Indoleamine 2, 3-dioxygenase 1; Treg: regulatory T cells; Cx43: Connexin43; S.C.: Salmonella

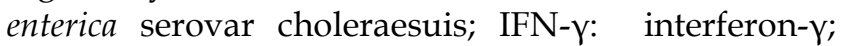
GCN2: kinase general control non- derepressible 2; AHR: aryl hydrocarbon receptor; Th: helper T cells; TGF- $\beta$ : transforming growth factor- $\beta$; 1-MT: 1-methyl-tryptophan; IFN- $\gamma$ : interferon- $\gamma ;$ TNF-a: tumor necrosis factor-a; DMEM: Dulbecco's Modified Eagle Medium.

\section{Acknowledgments}

This work was supported by grants from NSYSU-KMU JOINT RESEARCH PROJECT, (\#NSYSUKMU 106-P006). We thank Dr. MC Hung (The University of Texas M. D. Anderson Cancer Center) for generously providing K1735 cells.

\section{Author Contributions}

H.C.L and C.H.L conceived and designed the experiments; C.J.Y, W.K.W, Y.D.K. and H.C.L. performed the experiments; C.J.Y. and C.H.L analyzed the data; C.H.L contributed reagents/materials /analysis tools; Y.D.K. and C.H.L wrote the paper.

\section{Competing Interests}

The authors have declared that no competing interest exists.

\section{References}

1. Mendoza-Naranjo A, Saez PI, Johansson CC, Ramírez M, Mandakovic D, Pereda C, López MN, Kiessling R, Sáez J, Salazar-Onfray F. Functional gap junctions facilitate melanoma antigen transfer and cross-presentation between human dendritic cells. The Journal of Immunology 2007; 178: 6949-57.

2. Saccheri F, Pozzi C, Avogadri F, Barozzi S, Faretta M, Fusi P, Rescigno M. Bacteria-induced gap junctions in tumors favor antigen cross-presentation and antitumor immunity. Science Translational Medicine 2010; 2: 44ra57.

3. Goodenough DA, Paul DL. Gap junctions. Cold Spring Harbor Perspectives in Biology 2009; 1: a002576.

4. Naus CC, Laird DW. Implications and challenges of connexin connections to cancer. Nature Review Cancer 2010; 10: 435-41.

5. Tsuchida S, Arai Y, Kishida T, Takahashi KA, Honjo K, Terauchi R, Inoue H, Oda R, Mazda O, Kubo T. Silencing the expression of connexin 43 decreases inflammation and joint destruction in experimental arthritis. Journal of Orthopaedic Research 2013; 31: 525-30.

6. Mendoza-Naranjo A, Bouma G, Pereda C, Ramírez M, Webb KF, Tittarelli A, López MN, Kalergis AM, Thrasher AJ, Becker DL, Salazar-Onfray F. Functional gap junctions accumulate at the immunological synapse and contribute to T cell activation. The Journal of Immunology 2011; 187: 3121-32.

7. Viry E, Noman MZ, Arakelian T, Lequeux A, Chouaib S, Berchem G, Moussay E, Paggetti J, Janji B. Hijacker of the antitumor immune response: Autophagy is showing its worst facet. Frontiers in Oncology 2016; 18: 246

8. Brücher DM, Jamall IS. Cell-cell communication in the tumor microenvironment, carcinogenesis, and anticancer treatment. Cellular Physiology and Biochemistry 2014; 34: 213-43.

9. Fallarino F, Gu VC, Bianchi R, Orabona C, Spreca A, Fioretti MC, Puccetti P. T cell apoptosis by tryptophan metabolism. Cell Death \& Differentiation 2002; 9: 1069-77.

10. Munn DH, Mellor AL. Indoleamine 2,3 dioxygenase and metabolic control of immune responses. Trends in Immunology 2013; 34: 137-43.

11. Jochems CFM, Fernando RI, Kwilas AR, Donahue RN, Lepone LM, Grenga I, Kim YS, Brechbiel MW, Gulley JL, Madan RA, Heery CR, Hodge JW, Newton R, Schlom J, Tsang KY. The IDO1 selective inhibitor epacadostat enhances dendritic cell immunogenicity and lytic ability of tumor antigen-specific $\mathrm{T}$ cells. Oncotarget 2016; 7: 37762-72.

12. Balachandran VP, Cavnar MJ, Zeng S, Bamboat ZM, Ocuin LM, Obaid H, Sorenson EC, Popow R, Ariyan C, Rossi F, Besmer P, Guo T, Antonescu CR, Taguchi T, Yuan J, Wolchok JD, Allison JP, DeMatteo RP. Imatinib potentiates antitumor $\mathrm{T}$ cell responses in gastrointestinal stromal tumor through the inhibition of Ido. Nature Medicine 2011; 17: 1094-100.

13. Vacchelli E, Aranda F, Eggermont A, Sautès-Fridman C, Tartour E, Kennedy EP, Platten M, Zitvogel L, Kroemer G, Galluzzi L. Trial watch: IDO inhibitors in cancer therapy. Oncoimmunology 2014; 3: 957994.

14. Langcake P, Pryce RJ. The production of resveratrol by Vitis vinifera and other members of the Vitaceae as a response to infection or injury. Physiological Plant Pathology 1976; 9: 77-86.

15. Van der Wal SE, Vaneker M, Kox M, Braak G, Van Hees HW, Van den Brink IA, Van de Pol FM, Heunks LM, Van der Hoeven JG, Joosten LA, Vissers KC, Scheffer GJ. Resveratrol attenuates NF-K-binding activity but not cytokine production in mechanically ventilated mice. Acta Anaesthesiologica Scandinavica 2014; 58: 487-94.

16. de la Lastra CA, Villegas I. Resveratrol as an antioxidant and pro-oxidant agent: mechanisms and clinical implications. Biochemical Society Transactions 2007; 35: 1156-60.

17. Li T, Fan GX, Wang W, Li T, Yuan YK. Resveratrol induces apoptosis, influences IL-6 and exerts immunomodulatory effect on mouse lymphocytic leukemia both in vitro and in vivo. International Immunopharmacology 2007; 7: 1221-31.

18. Lee-Chang C, Bodogai M, Martin-Montalvo A, Wejksza K, Sanghvi M, Moaddel R, de Cabo R, Biragyn A. Inhibition of breast cancer metastasis by resveratrol-mediated inactivation of tumor-evoked regulatory $\mathrm{B}$ cells. The Journal of Immunology 2013; 191: 4141-51.

19. Noh KT, Cho J, Chun SH, Jang JH, Cha GS, Jung ID, Jang DD, Park YM. Resveratrol regulates naïve $\mathrm{CD} 8+\mathrm{T}$-cell proliferation by upregulating 
IFN- $\gamma$-induced tryptophanyl-tRNA synthetase expression. BMB Reports 2015; 48: 283-8.

20. Noh KT, Chae SH, Chun SH, Jung ID, Kang HK, Park YM. Resveratrol suppresses tumor progression via the regulation of indoleamine 2,3-dioxygenase. Biochemical and Biophysical Research Communications 2013; 431: 348-53.

21. Coley WB. Contribution to the Knowledge of Sarcoma. Annals of Surgery 1891; 14: $199-200$.

22. Forbes NS. Engineering the perfect (bacterial) cancer therapy. Nature Review Cancer 2010; 10: 785-94.

23. Pawelek JM, Low KB, Bermudes D. Tumor-targeted Salmonella as a novel anticancer vector. Cancer Research 1997; 15: 4537-44.

24. Kuan YD, Lee CH. Salmonella overcomes tumor immune tolerance by inhibition of tumor indoleamine 2, 3-dioxygenase 1 expression. Oncotarget 2016; 5: 374-85.

25. Lee $\mathrm{CH}$, Hsieh JL, Wu CL, Hsu PY, Shiau AL. T cell augments the antitumor activity of tumor-targeting Salmonella. Applied Microbiology and Biotechnology 2011; 90: 1381-8.

26. Tittarelli A, Guerrero I, Tempio F, Gleisner MA, Avalos I, Sabanegh S, Ortíz C, Michea L, López MN, Mendoza-Naranjo A, Salazar-Onfray F. Overexpression of connexin 43 reduces melanoma proliferative and metastatic capacity. British Journal of Cancer 2015; 113: 259-67.

27. Cheng YJ, Chang MY, Chang WW, Wang WK, Liu CF, Lin ST, Lee CH. Resveratrol enhances chemosensitivity in mouse melanoma model through connexin 43 upregulation. Environmental Toxicolology 2015; 30: 877-86.

28. Mezrich JD, Fechner JH, Zhang X, Johnson BP, Burlingham WJ, Bradfield CA. An interaction between kynurenine and the aryl hydrocarbon receptor can generate regulatory T cells. The Journal of Immunology 2010; 185: 3190-8.

29. Singh CK, George J, Ahmad N. Resveratrol-based combinatorial strategies for cancer management. Annals of the New York Academy of Sciences 2013; 1290: 113-21.

30. Popat R, Plesner T, Davies F, Cook G, Cook M, Elliott P, Jacobson E, Gumbleton T, Oakervee H, Cavenagh J. A phase 2 study of SRT501 (resveratrol) with bortezomib for patients with relapsed and or refractory multiple myeloma. Britich Journal of Haematology 2013; 160: 714-7.

31. Howells LM, Berry DP, Elliott PJ, Jacobson EW, Hoffmann E, Hegarty B, Brown K, Steward WP, Gescher AJ. Phase I randomized, double-blind pilot study of micronized resveratrol (SRT501) in patients with hepatic metastases--safety, pharmacokinetics, and pharmacodynamics. Cancer Prevention Research 2011; 4: 1419-25.

32. Toso JF, Gill VJ, Hwu P, Marincola FM, Restifo NP, Schwartzentruber DJ, Sherry RM, Topalian SL, Yang JC, Stock F, Freezer LJ, Morton KE, Seipp C, Haworth L, Mavroukakis S, White D, MacDonald S, Mao J, Sznol M, Rosenberg SA. Phase I study of the intravenous administration of attenuated Salmonella typhimurium to patients with metastatic melanoma. Journal of Clinical Oncology 2002; 20: 142-52.

33. Zhang M, Swofford CA, Forbes NS. Lipid A controls the robustness of intratumoral accumulation of attenuated Salmonella in mice. International Journal of Cancer 2014; 135: 647-57.

34. Arrach N, Cheng P, Zhao M, Santiviago CA, Hoffman RM, McClelland M. High-throughput screening for salmonella avirulent mutants that retain targeting of solid tumors. Cancer Research 2010; 70: 2165-70.

35. Tu DG, Chang WW, Lin ST, Kuo CY, Tsao YT, Lee CH. Salmonella inhibits tumor angiogenesis by downregulation of vascular endothelial growth factor. Oncotarget 2016; 7: 37513-23.

36. Chang WW, Lai CH, Chen MC, Liu CF, Kuan YD, Lin ST, Lee CH. Salmonella enhance chemosensitivity in tumor through connexin 43 upregulation. International Journal of Cancer 2013; 133: 1926-35.

37. Gupta SC, Kannappan R, Reuter S, Kim JH, Aggarwal BB. Chemosensitization of tumors by resveratrol. Annals of the New York Academy of Sciences 2011; 1215: $150-60$.

38. Zhang $Y$, Miwa S, Zhang N, Hoffman RM, Zhao M. Tumor-targeting Salmonella typhimurium A1-R arrests growth of breast-cancer brain metastasis. Oncotarget 2015; 20: 2615-22.

39. Ino $\mathrm{K}$, Yoshida $\mathrm{N}$, Kajiyama $\mathrm{H}$, Shibata $\mathrm{K}$, Yamamoto $\mathrm{E}$, Kidokoro $\mathrm{K}$ Takahashi N, Terauchi M, Nawa A, Nomura S, Nagasaka T, Takikawa O, Kikkawa F. Indoleamine 2,3-dioxygenase is a novel prognostic indicator for endometrial cancer. Britich Journal of Cancer 2006; 95: 1555-61,

40. Munn DH, Sharma MD, Baban B, Harding HP, Zhang Y, Ron D, Mellor AL. GCN2 kinase in T cells mediates proliferative arrest and anergy induction in response to indoleamine 2,3-dioxygenase. Immunity 2005; 22: 633-42.

41. Pallotta MT, Orabona C, Volpi C, Vacca C, Belladonna ML, Bianchi R, Servillo G, Brunacci C, Calvitti M, Bicciato S, Mazza EM, Boon L, Grassi F, Fioretti MC, Fallarino F, Puccetti P, Grohmann U. Indoleamine 2,3-dioxygenase is a signaling protein in long-term tolerance by dendritic cells. Nature Immunology 2011: 12: 870-78.

42. Opitz CA, Litzenburger UM, Opitz U, Sahm F, Ochs K, Lutz C, Wick W, Platten M. The indoleamine-2,3-dioxygenase (IDO) inhibitor 1-methyl-D-tryptophan upregulates IDO1 in human cancer cells. PLoS One 2011; 6: e19823.

43. Jochems C, Fantini M, Fernando RI, Kwilas AR, Donahue RN, Lepone LM, Grenga I, Kim YS, Brechbiel MW, Gulley JL, Madan RA, Heery CR, Hodge JW, Newton R, Schlom J, Tsang KY. The IDO1 selective inhibitor epacadostat enhances dendritic cell immunogenicity and lytic ability of tumor antigen-specific T cells. Oncotarget 2016; 7: 37762-72.
44. Zhang A, Hitomi M, Bar-Shain N, Dalimov Z, Ellis L, Velpula KK, Fraizer GC, Gourdie RG, Lathia JD. Connexin 43 expression is associated with increased malignancy in prostate cancer cell lines and functions to promote migration. Oncotarget 2015; 10: 11640-51. 